\section{REBREATHING METHOD FOR MEASUREMENT OF MIXED VENOUS}

BY

\section{E. J. M. CAMPBeLL,* M.D., Ph.D., M.R.C.P.}

AND

\section{J. B. L. HOWELL, Ph.D., M.B., M.R.C.P.}

From the Departments of Medicine, the Middlesex Hospital, London, and the Royal Infirmary, Manchester

This paper amplifies an earlier description of this method (Campbell and Howell, 1960b) in the light of further experience.

\section{Theoretical Background}

The aim of a rebreathing method is to bring the $\mathrm{CO}_{2}$ in a small bag into pressure equilibrium with the blood, so the $\mathrm{CO}_{2}$ tension can be measured in a gas rather than in a liquid (Campbell and Howell, 1960a). The problem is to achieve this equilibrium before the prevention of its excretion causes the pressure of the $\mathrm{CO}_{2}$ in the blood to rise excessively.

A rapid equilibrium will be achieved if a gas mixture is rebreathed which contains enough $\mathrm{CO}_{2}$ to enrich the alveolar gas to approximately the same tension as the mixed venous blood. If this mixture contains too much $\mathrm{CO}_{2}$, equilibrium will not be reached until the blood has carried away the excess; if it contains too little, $\mathrm{CO}_{2}$ will be evolved from the mixed venous blood. In either
The periods of time required for these two stages obviously depend on the volume of the bag, the volume of the lungs, the volume of the breaths, the blood $\mathrm{PCO}_{2}$, and the volume of pulmonary blood flow providing $\mathrm{CO}_{2}$. In practice the most important factor is the ratio of the tidal volume of breathing to the volume of the bag. Obviously, if the bag is too large too much time will be required to mix its contents with the lungs and raise the $\mathrm{PCO}_{2}$. On the other hand, if the bag is too small the subject will have insufficient "room" in which to breathe. The aim should be to have a bag volume about twice the tidal volume, but the ratio is not critical.

Fig. 1 shows the $\mathrm{PCO}_{2}$ at the mouth of a subject breathing in and out of a bag starting with $100 \% \mathrm{O}_{2}$ in the bag. The records were obtained from a normal subject with a resting tidal volume of 0.7 litre and a mixed venous $\mathrm{PCO}_{2}$ of $50 \mathrm{~mm}$. $\mathrm{Hg}$. He performed the two-stage procedure three times with different initial bag volumes (a, 1 1.; b, 2 1.; c, 4 1.). The three records have been superimposed to emphasize the influence of the tidal-volume: bag-volume ratio. In a this ratio was more than $1: 2$; in $b$ it was about $1: 3$; and in $c$ it was less than $1: 5$. Comparison of the three records during the first stage shows that the cyclical variation in $\mathbf{P C O}_{2}$ had almost disappeared, indicating fairly complete mixing between bag and lungs, after 60 seconds in a, 90 seconds in b, but not within 90 seconds in c. Furthermore, the $\mathrm{PCO}_{2}$ in the bag remained above mixed venous after 45 seconds in a and 75 seconds in $b$, but not in c. Hence, an initial bag volume varying from 1 to 21 . and a tidal volume ratio varying from $1: 1.5$ to $1: 3$ permitted the "preparation" of a suitable $\mathrm{PCO}_{2}$ in

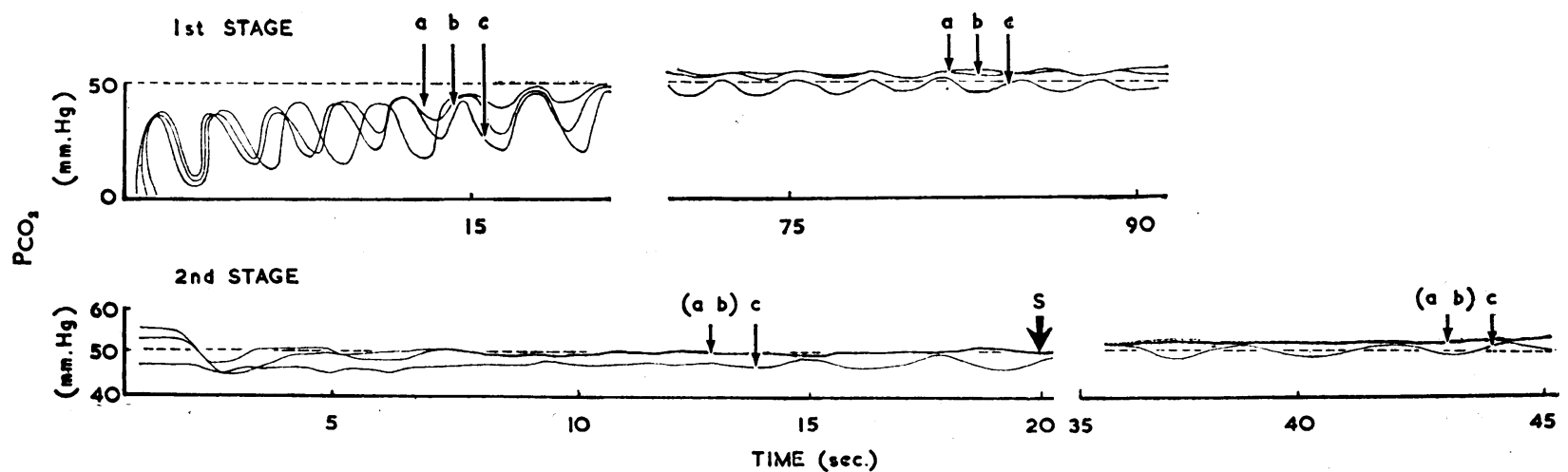

Fig. 1.- Continuous record of the two-stage procedure. Records of the $\mathrm{PCO}_{2}$ at the mouthpiece during rebreathing. The second stage followed the first after an interval of three to six minutes. Normal subject with a resting tidal volume of 0.71 . Three records superimposed to show influence of tidal-volume:bag-volume ratio. In curves a and b the bag Pco $\mathrm{b}_{2}$ was raised above mixed venous $\mathrm{PCO}_{2}$ during the first stage and good plateaux were obtained during the second stage. $a$, b, and $c=B a g$ volumes of 1,2 , and 4 l. respectively. $S=$ Usual time of sampling bag for analysis. Dotted line represents mixed venous Pco ${ }_{2}$.

case equilibrium will be delayed. Fortunately, the rate at which the $\mathrm{PCO}_{2}$ of the body rises when $\mathrm{CO}_{8}$ excretion is prevented is only about $6 \mathrm{~mm}$. $\mathrm{Hg} /$ minute, so that quite large limits of $\mathrm{CO}_{2}$ concentration in the initial rebreathing mixture can be tolerated.

The preparation of a gas mixture in $\mathrm{CO}_{2}$ equilibrium with the mixed venous blood therefore requires two stages : (1) The preparation of a $\mathrm{CO}_{2}$-containing mixture appropriate to the individual patient's $\mathrm{CO}_{2}$ tension. In our method each patient prepares his own $\mathrm{CO}_{2}$ mixture by rebreathing from a small bag of oxygen long enough to build up the $\mathrm{PCO}_{2}$ in the bag above the $\mathrm{PCO}_{2}$ of the blood. (2) The rebreathing of this mixture to achieve equilibrium with the blood before recirculation can alter this equilibrium significantly. the bag at the end of the first stage. A bag of 41 . was too large and a ratio of $1: 5$ too low for satisfactory results.

After a rest period of three to five minutes $a, b$, and $c$ were rebreathed for a further period of 45 seconds. The records obtained are shown in the lower part of Fig. 1. After a few oscillations $a$ and $b$ fuse and there is a plateau of constant $\mathrm{PCO}_{2}$ for 8 seconds. The initial oscillations represent mixing of the $\mathrm{CO}_{2}$ in the bag (where $\mathrm{PCO}_{2}$ was greater than mixed venous $\mathbf{P C O}_{2}$ ) with the $\mathrm{CO}_{2}$ in the lungs (where $\mathrm{PCO}_{2}$ was less than mixed venous $\mathrm{PCO}_{2}$ ) and the evolution or uptake of $\mathrm{CO}_{2}$ by the blood flowing through the lungs until there was complete equilibrium between bag, lungs, and blood. This equilibrium is represented by the plateau. The plateau was broken by the recirculation of blood which 
had been unable to give off its $\mathrm{CO}_{2}$. Records $\mathrm{a}$ and $\mathrm{b}$ then begin a slow rise at a rate of $6 \mathrm{~mm}$. $\mathrm{Hg}, \mathrm{PCO}_{2}$ per minute, which represents the rate of $\mathrm{CO}_{2}$ build-up in the blood when excretion is prevented. Stopping the procedure or sampling the bag at 20 seconds (S in Fig. 1) would give a $\mathrm{PCO}_{2}$ within $1 \mathrm{~mm}$. of the mixed venous plateau. Prolonging the period to 45 seconds allowed the $\mathrm{PCO}_{2}$ to rise $2 \mathrm{~mm}$. above mixed venous. Curve c, ootained when the bag was much too large, so that its $\mathrm{PCO}_{2}$ was not high enough at the end of the first stage, shows no plateau and its $\mathrm{PCO}_{2}$ at about 20 seconds is $4 \mathrm{~mm}$. below mixed venous $\mathrm{PCO}_{2}$. However, as the bag $\mathrm{PCO}_{2}$ was lower than blood $\mathrm{PCO}_{2}, \mathrm{CO}_{2}$ was given off more rapidly than in a or b, so that by 40 seconds bag $\mathrm{c}$ had risen $5 \mathrm{~mm}$. $\mathrm{Hg}$ and was close to the mixed venous figure.

Note that in the case of curve $c$ the underestimate of mixed venous $\mathrm{PCO}_{2}$ that would have been obtained had stage 2 been terminated after 20 seconds (S in Fig. 1) was cancelled by prolonging the rebreathing a further 20 seconds. This cancellation was obtained at the risk of the potential overestimate of $2 \mathrm{~mm} . \mathrm{Hg}$ which such prolongation would have caused had the procedure gone perfectly, as it did in a and b. This risk is often worth taking in practice (see Question 8, below).

\section{Equipment}

Fig. 2 shows the equipment we have found most generally useful in the rebreathing procedure. (1) The bag is a 1-gallon (4.5-lítre) (or 2-litre nominal capacity B.S. $3353: 1961)$ rebreathing or reservoir bag with outlet at the bottom, as manufactured by William Warne, Barking, Essex. This bag has the merit of inflating and deflating in such a manner that the volume changes can be judged by eye to $\pm 20 \%$. The loss of $\mathrm{CO}_{2}$ through the wall is not important if the analysis at the end of the rebreathing procedure is performed within 30 minutes. (2) Mouthpiece tap as designed by Campbell and Howell and supplied by Aimer Products, Rochester

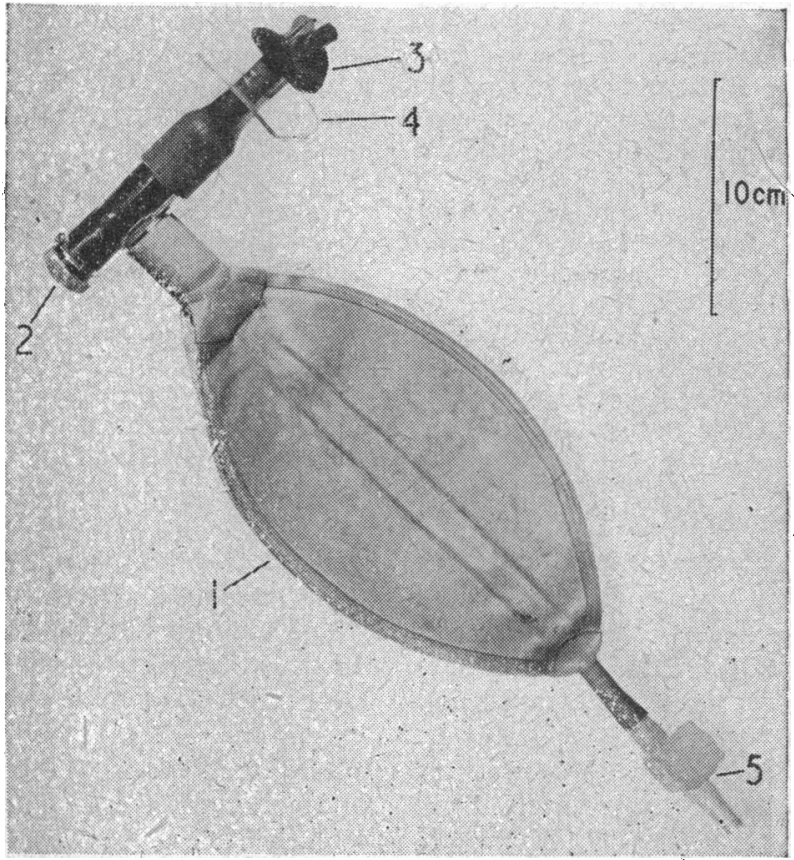

Fig. 2.-1, Rebreathing bag. 2, Mouthpiece tap. 3, Mouthpiece 4, Large plastic flange. 5, Tap.
Place, London N.W.1. (3) Spirometer mouthpiece as supplied by $H$. Kendrick, Woodford Green, Essex. (4) An additional flange $(4$ by 2 in. -10 by $5 \mathrm{~cm}$.) made from 2-mm.-thick polyvinylchloride sheeting (non-toxic Portex, 0.082 in. ( $2 \mathrm{~mm}$.)-thick SH 95 : Portland Plastics, Hythe, Kent) or a similar flexible firm but not hard material with a central aperture which snugly fits the stem of the spirometer mouthpiece. The use of this is explained later. (5) "Polythene" tap of 5-mm. bore. This tap has several advantages, most important of which is that its external taper fits a wide range of tracheostomy and endotracheal tubes. Unfortunately the firm which made it (Portland Plastics, Hythe, Kent) no longer does so, and there are few to be obtained from stockists. A fair substitute is a vulcanite douche fitting tap as made by J. G. Franklin, Dalston, London E.8.

\section{Details of Technique}

Rather than repeat the description previously published, we wish to discuss the technique in the form of answers to the questions that are most commonly asked. Before doing so we would like to stress that most of these questions do not arise if those wishing to apply the method understand its principles.

Question 1: How accurate is the method? Answer: Accurate enough for all clinical purposes and probably more accurate than many technically more sophisticated methods. Put quantitatively, the rebreathing methods can probably estimate the $\mathrm{PCO}_{2}$ of the oxygenated mixed venous blood with an accuracy of $\pm 1 \mathrm{~mm}$. $\mathrm{Hg}$ or less. Actual comparisons cannot improve these estimates of accuracy for two reasons: firstly, mixed venous blood has not been sampled at the same time as a rebreathing procedure is carried out (the comparisons that have been made involved sampling at different times); secondly, even were it sampled there is no method of measuring blood $\mathrm{PCO}_{2}$ which is more accurate than $\pm 2 \mathrm{~mm}$. $\mathrm{Hg}$.

Caution must always be used in judging values obtained with a rebreathing method against estimates of arterial $\mathrm{PCO}_{2}$ which, except in expert hands, are liable to error firstly because of the technical difficulties of all methods for blood analysis, and secondly because the arterial $\mathrm{PCO}_{2}$ is unstable and changes readily with alteration of the breathing. An inexpertly performed arterial puncture, particularly if the blood is withdrawn in less than a minute, is liable to errors due to disturbance of breathing which alters arterial $\mathrm{PCO}_{2}$. Disturbance of the breathing during the rebreathing procedure. on the other hand. does not affect the result. If doubt is raised by a value obtained by the rebreathing meihod, rather than turning to arterial sampling. it is more profitable and expeditious to repeat the rebreathing procedure. reducing the bag size and prolonging the rebreathing periods (see Question 8, below).

Question 2: What is the reason for subtracting $6 \mathrm{~mm}$. $\mathrm{Hg}$ from the mixed venous $\mathrm{PCO}_{2}$ in the estimating of arterial $\mathrm{PCO}_{2}$ ? Answer: This is the average arterial-oxygenated mixed venous $\mathrm{PCO}_{2}$ difference in a resting subject. Hackney et al. (1958), and we found that subtraction of 6 from the mixed venous $\mathrm{PCO}_{2}$ estimated the arterial $\mathrm{PCO}_{2}$ with an accuracy of $\pm 2-3 \mathrm{~mm}$. Hg. We do not ourselves use this subtraction except for comparative purposes. because the resting mixed venous $\mathrm{PCO}_{2}$ has at least as good a claim as the arterial to represent the $\mathrm{PCO}_{2}$ of the body fluids. See also question 1 above. We emphasize that the measurements must be made in the resting subject. otherwise the mixed venous $\mathrm{PCO}_{2}$ does not reflect the ventilatory status.

Question 3 : What do you mean by "oxygenated" mixed venous blood? Answer: During the equilibration between 
the $\mathrm{CO}_{2}$ in the lungs and that in the blood the haemoglobin becomes saturated with oxygen which is at a higher pressure in the lungs than in the "true" mixed venous blood. The effect of this is to raise the partial pressure of the $\mathrm{CO}_{2}$ in the blood above its "true" value. The overestimate caused by oxygenation of the haemoglobin depends upon several factors and is probably about $2 \mathrm{~mm}$. $\mathrm{Hg}$ in a resting subject. This $2 \mathrm{~mm}$. is included in the empirically determined $6 \mathrm{~mm}$. referred to in question 2 above. (For a more detailed discussion see Campbell and Howell, 1960a.)

Question 4: Why use $\mathrm{O}_{2}$ as the initial gas mixture ? Answer: Oxygen is not essential. We use it because it is readily available and precludes the possibility of anoxia during the rebreathing procedure. Expired air or $\mathrm{CO}_{2}-\mathrm{O}_{2}$ mixtures can be used, but apart from shortening the initial rebreathing period by a small and unpredictable amount they have no advantage over $\mathrm{O}_{2}$.

Question 5: Why do you recommend using 1.5-2 1. of $\mathrm{O}_{2}$ in the bag ? Answer: This volume is big enough for the largest tidal volumes one is likely to encounter, and is also satisfactory for adults with normal ventilation. If the movement of the bag at the end of half a minute indicates that the tidal volume is less than half the bag volume, then some of the gas is emptied. It is easier to empty a bag which is too big than to fill a bag which is too small, and it is less distressing to the patient.

Question 6: Why do you recommend that the initial rebreathing period should be $1 \frac{1}{2}$ minutes ? Answer: Inspection of Fig. 1 will show that the bag $\mathrm{Pco}_{2}$ is brought conveniently above the mixed venous $\mathrm{PCO}_{2}$ in $1 \frac{1}{2}$ minutes, provided the tidal-volume:bag-volume ratio is adequate (Fig. 1, $a$ and $b$ ). The time is not critical. If ventilation is very small (as judged by the movement of the bag) we often prolong the initial period to 2 minutes. We are often told that some patients will not tolerate this $1 \frac{1}{2}$-minute period. We find that a mixture of firmness and encouragement. particularly asking the patient to breathe deeply at an instructed rate (which reduces any sense of suffocation) usually overcomes this difficulty. If the patient cannot achieve 1 minute under these conditions we use two separate periods of as great a duration as the patient will tolerate. It must be remembered that distress evinced within half a minute cannot be attributed to an intolerable rise of $\mathrm{PCO}_{2}$ because the mixing in the lungs and circulation to the brain impose a delay of this duration.

Question 7 : As the $\mathrm{PCO}_{2}$ in the bag after the first stage is close to mixed venous $\mathrm{PCO}_{2}$, why not take this value and do without the second stage? Answer: The first stage can be used to estimate mixed venous $\mathrm{PCO}_{2}$ with an accuracy of about $\pm 5 \mathrm{~mm}$. $\mathrm{Hg}$. For many clinical purposes this is adequate. The second stage provides a "fine adjustment" which probably estimates the mixed venous $\mathrm{PcO}_{2}$ to within $\pm 1 \mathrm{~mm}$. $\mathrm{Hg}$ (see below).

Question 8: Why do you recommend that the second stage be 20 seconds? Answer: Observation with a rapid $\mathrm{CO}_{2}$ analyser shows that the plateau of equilibrium is usually achieved within 10-15 seconds (Fig. 1). If the subject is co-operative and/or the circulatory rate is thought to be increased, we often ask him to breathe deeply and then stop the procedure after four breaths in 10-12 seconds. On the other hand, if the breathing is shallow we prolong the rebreathing to $30-40$ seconds. By doing so we accept a potential overestimate of $2-3 \mathrm{~mm}$. $\mathrm{Hg}$. due to recirculation as insurance against inadequate mixing (see discussion of Fig. 1, c, above). Clinically this problem usually arises in cases of suspected underventilation, and the risk of an overestimate of $2 \mathrm{~mm}$. $\mathrm{Hg}$ is well worth accepting.

Question 9: How do you avoid leaks, particularly when the subject is uncooperative? Answer: By the use of the mouthpiece arrangement shown in Fig. 2. With a co-operative subject the small mouthpiece is adequate. For an unconscious or uncooperative subject the large flange is slid up to the smaller flange ; the large flange is then put into the patient's mouth by peeling the lips over it; the mouthpiece is then pulled gently away from the mouth while making a sandwich of the patient's lips between the flange and one's hand. This arrangement is usually more satisfactory than a mask.

Question 10: Can the method be used with apnoeic or paralysed patients? Answer: Provided a leak-proof connexion is made the method works very well by squeezing the bag to achieve intermittent positive-pressure breathing. Suitable connexions for use with endotracheal or tracheostomy tubes are available. If for any reason a leak-proof connexion cannot be obtained, ventilation by trunk compression (as in artificial respiration) usually can be used.

Question 11: Does the bad mixing of inspired air in the lungs of patients with conditions such as emphysema hinder the method? Answer: Not significantly. The gas in the parts of the lungs which are poorly ventilated and well perfused already has a $\mathrm{PCO}_{2}$ close to that of mixed venous blood. On the other hand, parts of the lungs which are overventilated in relation to their blood flow are usually also well ventilated in relation to their volume, so their gas is rapidly mixed with that in the bag. Parts of the lungs which are of large volume, having little blood flow (that is, a high ventilation:perfusion ratio) but also a low turnover rate (that is, a low ventilation : volume ratio), must hinder the attainment of equilibrium but do not prevent it. In practice it is easier to achieve equilibrium in a patient with a large dead space than in one with the same $\mathrm{PCO}_{2}$ but a normal dead space. The larger breaths in the subject with the large dead space accelerate mixing more than the dead space itself hinders it. The most difficult problems are presented by patients with normal lungs and very shallow breathing. In the limit, of course, the method cannot work if there is no breathing.

Question 12: Is the method applicable to patients with intracardiac shunts ? Answer: Rapid recirculation through left-to-right shunts may prevent the attainment of a plateau such as is seen in Fig. 1 ( $a$ and $b$ ) and may invalidate the trial-and-error procedure as described by Collier (1956). Our method does not depend upon recognition of this plateau, and the procedure in the first stage ensures that the $\mathrm{PcO}_{2}$ in the bag cannot be far from the mixed venous $\mathrm{PCO}_{2}$, so, in the absence of comparative measurements, we do not think that the rapid recirculation can introduce an error of more than 2-3 mm. Right-to-left shunts do not prevent equilibration with the mixed venous $\mathrm{PCO}_{2}$ during the rebreathing method.

Question 13: Which is the best $\mathrm{CO}_{2}$ analyser for use with the method? Answer: A rapid continuous $\mathrm{CO}_{2}$ analyser such as an infra-red analyser is the instrument of choice because, firstly, it enables the procedures to be checked as in Fig. 1, so that equilibration can be verified; and, secondly, the two-stage procedure can be replaced by Collier's one-stage trial-and-error method, which is more rapid and requires less tolerance or co-operation from the subject. Such analysers, however, are not readily portable, and, if they are switched off, time is required for warming up and calibration. Simple cheap analysers can be used if the two-stage procedure is employed. We therefore recommend a rapid continuous analyser as being most suitable for use in fixed installations when speed and convenience are paramount considerations and when the analyser can be kept permanently sivitched on and, regularly in use (Campbell and Howell, 1960c).

Several people have approached us with problems in the use of the simplified Haldane apparatus described in conjunction with the rebreathing method (Campbell, 1960). Few of these problems were peculiar to the apparatus, and most could have been overcome by reference to standard accounts of gas-analysis techniques (for example, Haldane and Graham, 1935 ; Consolazio, Johnson and Marek, 1951). The commonest errors in its use are: (1) failure to test for leaks by occasional blank analyses of room air; (2) failure to maintain a trace of acid in the gas burette; (3) misreading of the 
volume-marking for the \% marking or vice versa, or reading the acid meniscus instead of the mercury; and (4) taking the $\% \mathrm{CO}_{2}$ as being the $\mathrm{PCO}_{2}$ without multiplication by (barometric pressure -47 ).

\section{Summary}

Factors affecting the two-stage equilibration rebreathing procedure for the measurement of mixed venous $\mathrm{PCO}_{2}$ are discussed. The most important practical conclusion is that the volume of gas in the bag should not be more than twice the tidal volume; but the exact ratio is not critical.

Suitable equipment is described.

Practical problems and variations in technique are described in detail.
We are grateful to the many people who have told us of their experience and difficulties, and particularly to those who have suggested modifications and improvements. Dr. A. S. E. Fowle helped with the experiment shown in Fig. 1.

\section{REFBRENCES}

Campbell, E. J. M. (1960). Brit. med. J., 1, 457 and Howell, J. B. L. (1960a). pH and Blood Gas Measurement: Methods and Interpretations, edited by R. Woolmer. Churchill, London.$$
\text { (1960c) Brit. med. J., }
$$

- (1960c). Ibid., 1, 1209.

Collier, C. R. (1956). J.; appl. Physiol., 9, 25.

Consolazio, C. F., Johnson, R. E., and Marek, E. (1951) Metabolic Methods, p. 312. Kimpton, London.

Hackney, J. D., Sears, C. H., and Collier, C. R. (1958). Ibid. $12,425$.

Haldane, J. S., and Graham, J. I. (1935). Methods of Air Analysis, 4th ed. Griffin, London.

\title{
CONVULSIONS AND TELEVISION VIEWING
}

\author{
BY

\section{S. N. PANTELAKIS, M.D. Research Associate \\ B. D. BOWER, M.D., M.R.C.P., D.C.H. Senior Lecturer}

\section{H. DOUGLAS JONES, * B.Sc.} \\ Medical Student \\ From the Department of Paediatrics and Child Health, University of Birmingham, and the Children's Hospital, \\ Birmingham
}

In this country $90 \%$ of children aged between 5 and 15 live in households that have a television set, and in the winter these children spend an average of two and three-quarter hours watching their sets (Abrams, 1961). The television picture is produced by intermittent illumination. Since intermittent photic stimulation is a well-known provocative method for producing epileptic discharges, it is surprising that only a few reports of television-induced convulsions have appeared (Ismay, 1958 ; Klapetek, 1959 ; Lagergren and Hansson, 1960 ; Richter, 1960; Gastaut, Régis, Bostem, and Beaussart, 1960 ; Pallis and Louis, 1961; Mawdsley, 1961 ; Fischer-Williams, 1961 ; Madden, 1961 ; Garvie, 1961; Lange, 1961). With one exception, each of these authors described only a few cases. However, it is clear from talking to colleagues that such cases are not very rare nowadays, and in this hospital in the past two years we have seen 14 children with the condition. In the same period 243 children in the age range when exposure to television occurs (4-15 years) have been referred to our E.E.G. department with a diagnosis of epilepsy. This gives an incidence of television-induced epilepsy among epileptic children of $5.7 \%$.

We have investigated these children by electroencephalography (E.E.G.), using the special techniques of intermittent photic stimulation (I.P.S.) described below. The questions we have tried to answer are: (1) Is there any common factor in the E.E.G. of these patients which distinguishes them from epileptic children whose convulsions are not associated with television viewing? (2) Are there any differences in the E.E.G.S within the group? (3) If so, are these differences related to any clinical differences?

\section{Material}

The age range of the 14 children (six boys and eight girls) was 8 to 14 years. There was no suggestion of brain damage in the history of birth or neonatal period or of subsequent development, and physical examination was normal in every case. In only one child was there a family history of convulsions. Intelligence assessments were not carried out, but all children were attending an ordinary school and seemed of average intelligence, except one who was attending a school for the educationally subnormal.

In nine cases the convulsions had occurred only while watching television. Six of these children had had only one convulsion each. By contrast, one child had had eight, all since the family had installed a set, and all while watching it. He still insists on watching it, sitting about $2 \mathrm{ft}$. $(60 \mathrm{~cm}$.) away. It is he who is educationally subnormal. The remaining five have had some convulsions under other circumstances. We considered television-viewing to be more than coincidental in these five because they showed very marked sensitivity to I.P.S. Moreover, three of them showed clinical evidence of sensitivity to flickering light ; two had had their only major fits during television-viewing, while at other times their fits had been minor; and the third had on several occasions felt giddy and developed a headache when he walked beside railings on a sunny day or looked at a fluorescent lamp.

The type of convulsion occurring during televisionviewing was grand $\mathrm{mal}$ in 13 cases and petit $\mathrm{mal}$ in one

We have inquired into the circumstances surrounding the convulsions, with particular reference to the distance of the child from the screen, whether the picture was normal or abnormal-that is, whether it was clear or blurred, steady or flickering-and, if abnormal, whether the child was adjusting the set at the time. Seven patients were near the screen (within 2 feet ; $60 \mathrm{~cm}$.) ; of these, four were adjusting the set because the picture was abnormal, and three preferred to sit near the screen rather than at the usual distance.

Patient 7.-A girl aged 14 with an unremarkable previous history had watched television for three and a half years 